\title{
KETERAMPILAN MENULIS KREATIF CERPEN MENGGUNAKAN MEDIA AUDIO SISWA KELAS XII SMAN 1 KECAMATAN PAYAKUMBUH
}

\author{
Wirda Linda \& Ayu Armia Gusti \\ Pendidikan Bahasa dan Sastra Indonesia \\ STKIP Abdi Pendidikan \\ wirdalinda.dwi@gmail.com
}

Naskah diterima: 16 Januari 2017; direvisi: 20 April 2017; disetujui: 21 April 2017

\begin{abstract}
Writing skills is activities of language serves to produce written language. Writing can improve intelligence, develop initiative, creativity, stimulate the willingness and ability to gather information. Students' skills in short stories writing activities is still lacking. This things because teachers use less attractive media. Thus, this study uses audio media to increase students' interest in writing. This study aimed to describe the shost story intrinsic elements and the use of capital letters in Creative Short Story Writing Skills Using Media Audio Class XII SMAN I Payakumbuh District.This research is a quantitative research using descriptive method. The study population class XII students totaling 217 consists of 8 classes. Writer to perform sampling with random random sampling techniques. The instrument of this study is to test performance. Data analysis in the study: to check the results to write short stories, analyze the data and provide a score based on indicators, and put forward the test results to the classification skills by using a scale of 10.Results showed that average value of 90.8 are in the range of 86-95\% with good qualification. Creative writing skills are evaluated from two short stories specified indicators are: (1) short story creative writing skills in terms of the intrinsic elements of the short story is the 100 that are in the range of 96-100\% with impeccable qualifications; (2) The short story creative writing skills in terms of capitalization was $80.8 \%$ are in the 76-85 range with good qualifications. Thus, we can conclude the students are already capable in writing short stories as well as the use of capital letters in writing.
\end{abstract}

Keywords: writing, short story, media, lesson

\begin{abstract}
ABSTRAK
Keterampilan menulis merupakan salah satu aktifitas berbahasa yang berfungsi memproduksi bahasa secara tertulis. Menulis dapat meningkatkan kecerdasan, mengembangkan daya inisiatif dan kreatifitas, serta merangsang kemauan dan kemampuan mengumpulkan informasi. Kemampuan siswa dalam menulis kreatif cerpen masih kurang. Hal ini karena strategi pembelajaran yang digunakan guru kurang menarik. Dengan demikian, penelitian ini menggunakan media audio agar minat siswa dalam menulis meningkat. Penelitian ini bertujuan mendeskripsikan unsur intrinsik cerpen dan penggunaan huruf kapital dalam Keterampilan Menulis Kreatif Cerpen Menggunakan Media Audio Siswa Kelas XII SMAN I Kecamatan Payakumbuh. Jenis penelitian ini adalah penelitian kuantitatif menggunakan metode deskriptif. Populasi penelitian siswa kelas XII yang berjumlah 217 terdiri dari 8 kelas. Penulis melakukan pengambilan sampel melalui teknik sampel random acak (cluster random sampling) dengan cara mengundi dan
\end{abstract}


terpilih kelas XII IPA 2 yang berjumlah 25 orang siswa. Instrumen penelitian ini adalah tes unjuk kerja. Analisis data dilakukan dengan memeriksa hasil menulis cerpen, menganalisis data dan memberikan skor berdasarkan indikator dan mengemukakan hasil tes ke dalam pengklasifikasian keterampilan dengan menggunakan skala 10. Hasil analisis data menunjukkan rata-rata nilai 90,8 berada pada rentangan $86-95 \%$ dengan kualifikasi baik sekali. Keterampilan menulis kreatif cerpen yang ditinjau dari dua indikator yang ditentukan adalah: (1) keterampilan menulis kreatif cerpen ditinjau dari unsur intrinsik cerpen adalah 100 berada pada rentangan 96-100\% dengan kualifikasi sempurna; (2) keterampilan menulis kreatif cerpen ditinjau dari penggunaan huruf kapital adalah 80,8 berada pada rentangan 76-85\% dengan kualifikasi baik. Jadi, dapat disimpulkan siswa sudah mampu dalam menulis kreatif cerpen beserta penggunaan huruf kapital dalam menulis.

Kata kunci: menulis, cerpen, media, pembelajaran

\section{PENDAHULUAN}

Terdapat empat aspek keterampilan berbahasa yang harus dikuasai dalam pembelajaran bahasa Indonesia, aspek tersebut diantaranya menyimak, menulis, membaca dan berbicara. Setiap keterampilan berbahasa tersebut memiliki hubungan yang sangat erat satu sama lainnya dan tidak bisa dipisahkan, karena keempat keterampilan berbahasa itu pada dasarnya merupakan suatu kesatuan yang utuh. Pentingnya keterampilan menulis tidak hanya terlihat pada suatu keberadaannya, nilai, fungsi dan proses kegiatan saja, tetapi juga wujud yang dihasilkannya.

Menulis sebagai aktifitas berbahasa tidak dapat dilepaskan dari kegiatan berbahasa lainnya. Apa yang diperoleh melalui menyimak, membaca, berbicara akan memberinya masukan berharga untuk kegiatan menulis. Meskipun demikian, menulis sebagai suatu aktifitas berbahasa tulis memiliki perbedaan, terutama dengan kegiatan berbahasa lisan. Perbedaan itu menyangkut cara konteks serta hubungan antar unsur yang terlibat, yang berimplikasi pada ragam bahasa yang digunakan.

Sebagai suatu keterampilan berbahasa, menulis merupakan kegiatan yang kompleks karena penulis dituntut untuk dapat menyusun dan mengorganisasikan isi tulisannya serta menuangkan dalam formulasi ragam bahasa tulis dan konvensi bahasa penulis an lainnya. Dibalik kerumitannya, menulis mengandung banyak manfaat bagi pengembangan mental, intelektual, dan sosial seseorang. Menulis dapat meningkatkan kecerdasan, mengembangkan daya inisiatif dan kreatifitas, menumbuhkan keberanian, serta merangsang kemauan dan kemampuan mengumpulkan informasi. Menulis merupakan kegiatan komunikasi berupa penyampaian pesan secara tertulis kepada pihak lain. Aktifitas menulis melibatkan unsur penulis sebagai penyampaian pesan atau isi tulisan, saluran atau media tulisan, dan pembaca sebagai penerima pesan.

Pengajaran bahasa Indonesia tidak akan lepas dari kegiatan menulis. Menulis tidak dapat dipisahkan dalam proses belajar mengajar di kelas. Melalui kegiatan menulis, seseorang dapat mengungkapkan gagasan dan pikirannya kedalam tulisan. Keterampilan menulis sama seperti halnya dengan kemampuan berbahasa yang lain, yang tidak datang dengan sendirinya, melainkan harus melalui latihan dan praktik yang banyak dan teratur secara terus menerus.

Masalah yang sering muncul dalam pembelajaran menulis menurut wawancara penulis dengan guru mata pelajaran Bahasa Indonesia adalah kurangnya kemampuan siswa menggunakan bahasa Indonesia yang baik dan benar. Hal tersebut dapat dilihat dari pilihan kata yang kurang tepat, kalimat 
yang kurang efektif, sukar mengungkapkan gagasan karena kesulitan memilih kata ketika membuat kalimat, bahkan kurang mampu mengembangkan ide secara teratur dan sistematis. Selain itu, siswa kurang berminat dalam menulis sehingga permasalahan tersebut menjadi kendala dalam menulis, khususnya dalam menulis karangan yaitu cerpen.

Menulis akan tetap berharga, sebab menulis membantu seseorang berpikir lebih mudah. Selanjutnya, menurut Nuruddin (2010: 4) menyatakan menulis adalah segenap rangkaian kegiatan seseorang dalam mengungkapkan gagasan dan menyampaikannya melalui bahasa tulis kepada orang lain agar mudah dipahami. Sejalan dengan itu, menulis sebagai suatu rangkaian kegiatan seseorang dalam mengungkapkan gagasan dan mengungkapkan melalui bahasa tulis kepada pembaca, untuk dipahami tepat seperti yang dimaksudkan oleh pengarang.

Kusumaningsih (2007: 123) berpendapat menulis merupakan suatu proses kreatif yang banyak melibatkan cara berpikir divergen (menyebar) dari pada konvergen (memusat). Karena, makna kata mencipta adalah membuat sesuatu yang baru (yang sebelumnya belum pernah ada) maka karya tulis kreatif itu haruslah bersifat baru. Menulis kreatif biasanya muncul dari dalam diri orang yang mempunyai kemampuan berpikir kreatif, sehingga antara kemampuan menulis kreatif dan berpikir kreatif saling terkait sangat kuat (Wardhana dan Ardianto 2007:28).

Menurut Kosasih (2008:53), menjelaskan cerpen adalah cerita yang menurut fisiknya berbentuk pendek. Ukuran panjang-pendeknya suatu cerita memang relatif. Kemudian Poe (dalam Nurgiyantoro, 1998:10) menyatakan, bahwa cerpen adalah sebuah cerita yang habis dibaca dalam sekali duduk, kira-kira berkisar antar setengah sampai dua jam, suatu hal yang kiranya tak mungkin dilakukan untuk sebuah novel. Namun, pada umumnya cerita pendek merupakan cerita yang habis dibaca sekitar sepuluh menit atau setengah jam.

Sudjana dan Rivai (2010: 129) berpendapat bahwa media audio untuk pengajaran, dimaksudkan sebagai bahan yang mengandung pesan dalam bentuk auditif (pita suara atau piringan suara), yang dapat merangsang pikiran, perasaan, perhatian dan kemauan peserta didik, sehingga terjadi proses belajar-mengajar. Menggunakan media audio di sini memasukkan dua keterampilan berbahasa, yaitu mendengar dan menulis. Maka dari itu, dua aspek keterampilan tersebut digunakan bersamaan karena dapat merangsang peserta didik untuk belajar dan mendengar media audio yang diputar sekalian menulis cerpen dari hasil mendengar media audio yang diputar. Media audio yang digunakan yaitu Lagu Ratu Sikumbang berjudul Nyao Pulang $\mathrm{Ka}$ Badan, di sini siswa disuruh menulis cerpen dengan memasukkan unsur-unsur intrinsik cerpen. Lagu Nyao Pulang $\mathrm{Ka}$ Badan dipilih karena lagu tersebut lagu minang yang begitu popular di kalangan masyarakat dan enak di dengar di telinga kita semua, banyak siswa menyukai lagu tersebut. Maka dari itu, lagu Nyao Pulang $K a$ Badan di putarkan di saat proses penelitian ini terjadi.

\section{METODE PENELITIAN}

Jenis penelitian ini adalah penelitian kuantitatif. Metode yang digunakan dalam penelitian ini adalah metode deskriptif. Penelitian deskriptif menurut Sugiyono (2012:8) adalah analisis data bersifat kuantitatif/statistik, dengan tujuan untuk menguji hipotesis yang telah ditetapkan. Maka dari itu, dalam penelitian ini penggunaan metode deskriptif bertujuan untuk mendeskripsikan keterampilan menulis kreatif cerpen menggunakan media audio siswa kelas XII SMAN 1 Kecamatan Payakumbuh menggunakan statistik dalam menguji hipotesis. 


\section{HASIL DAN PEMBAHASAN}

Hasil analisis data menunjukkan bahwa tingkat Keterampilan Menulis Kretaif Cerpen Menggunakan Media Audio Siswa Kelas XII SMA Negeri 1 Kecamatan Payakumbuh secara umum dengan ratarata nilai 90,8 berada pada rentangan $86-$ 95\% dengan kualifikasi baik sekali. Berdasarkan dari nilai keterampilan menulis cerpen siswa kelas XII secara umum, keterampilan menulis kreatif cerpen siswa kelas XII sudah berada diatas KKM yang telah ditentukan yaitu 78 .

Data yang diperoleh melalui tes unjuk kerja yakni tes menulis kreatif cerpen berdasarkan indikator penelitian yaitu unsur intrinsik cerpen dan penggunaan huruf kapital. Pada masing-masing unsur diberikan skor tertinggi 5 dan skor terendah 1. Total skor dari aspek kedua penilaian tersebut adalah 10 .

Hasil analisis data menunjukkan bahwa tingkat Keterampilan Menulis Kreatif Cerpen Menggunakan Media Audio Siswa Kelas XII SMA Negeri 1 Kecamatan
Payakumbuh dilihat indikator penilaian unsur intrinsik cerpen dengan rata-rata nilai 100 berada pada rentangan 96-100\% dengan kualifikasi sempurna. Selanjutnya, tingkat Keterampilan Menulis Kreatif Cerpen Menggunakan Media Audio Siswa Kelas XII SMA Negeri 1 Kecamatan Payakumbuh dilihat dari indikator penilaian penggunaan huruf kapital dengan rata-rata nilai 80,8 berada pada rentangan 76-85\% dengan kualifikasi baik.

Menulis Kreatif Cerpen Menggunakan Media Audio Siswa Kelas XII SMA Negeri 1 Kecamatan Payakumbuh dapat diketahui setelah skor yang diperoleh sampel diolah menjadi nilai menggunakan rumus Abdurrahman dan Ratna (2003: 264) berikut ini.

Untuk lebih jelasnya Keterampilan Menulis Kreatif Cerpen Menggunakan Media Audio Siswa Kelas XII SMA Negeri 1 Kecamatan Payakumbuh dapat dilihat pada tabel berikut ini.

Tabel 1. Nilai Keterampilan Menulis Kreatif Cerpen Menggunakan Media Audio dari Kedua Aspek yang Dinilai

\begin{tabular}{ccccccc}
\hline \multirow{2}{*}{ No } & Kode Siswa & \multicolumn{2}{c}{ Aspek yang Dinilai } & \multirow{2}{*}{$\begin{array}{l}\text { Total } \\
\text { Skor }\end{array}$} & Nilai & Kualifikasi \\
\cline { 2 - 4 } & & UIC & HK & & & \\
\hline 1 & 01 & 5 & 3 & 8 & 80 & Baik \\
\hline 2 & 02 & 5 & 4 & 9 & 90 & Baik Sekali \\
\hline 3 & 03 & 5 & 4,5 & 9,5 & 95 & Baik Sekali \\
\hline 4 & 04 & 5 & 4,5 & 9,5 & 95 & Baik Sekali \\
\hline 5 & 05 & 5 & 3 & 8 & 80 & Baik \\
\hline 6 & 06 & 5 & 5 & 10 & 100 & Sempurna \\
\hline 7 & 07 & 5 & 5 & 10 & 100 & Sempurna \\
\hline 8 & 08 & 5 & 4 & 9 & 90 & Baik sekali \\
\hline 9 & 09 & 5 & 3 & 8 & 80 & Baik \\
\hline 10 & 010 & 5 & 2 & 7 & 70 & Lebih dari Cukup \\
\hline 11 & 011 & 5 & 3,5 & 85 & 85 & Baik \\
\hline 12 & 012 & 5 & 5 & 10 & 100 & Sempurna \\
\hline 13 & 013 & 5 & 4,5 & 95 & 95 & Baik sekali \\
\hline 14 & 014 & 5 & 5 & 10 & 100 & Sempurna \\
\hline 15 & 015 & 5 & 4 & 9 & 90 & Baik sekali \\
\hline 16 & 016 & 5 & 3 & 8 & 80 & Baik \\
\hline 17 & 017 & 5 & 5 & 10 & 100 & Sempurna \\
\hline 18 & 018 & 5 & 5 & 10 & 100 & Sempurna \\
\hline 19 & 019 & 5 & 5 & 10 & 100 & Sempurna \\
\hline 20 & 020 & 5 & 5 & 10 & 100 & Sempurna \\
\hline
\end{tabular}




\begin{tabular}{ccccccc}
\hline \multirow{2}{*}{ No } & \multirow{2}{*}{ Kode Siswa } & \multicolumn{2}{c}{ Aspek yang Dinilai } & \multirow{2}{*}{$\begin{array}{l}\text { Total } \\
\text { Skor }\end{array}$} & Nilai & Kualifikasi \\
\cline { 3 - 4 } & & UIC & HK & & & \\
\hline 21 & 021 & 5 & 3 & 8 & 80 & Baik \\
\hline 22 & 022 & 5 & 5 & 10 & 100 & Sempurna \\
\hline 23 & 023 & 5 & 5 & 10 & 100 & Sempurna \\
\hline 24 & 024 & 5 & 3 & 8 & 80 & Baik \\
\hline 25 & 025 & 5 & 3 & 8 & 80 & Baik \\
\hline Jumlah & $\mathbf{1 2 5}$ & $\mathbf{1 0 2}$ & $\mathbf{2 2 7}$ & $\mathbf{2 2 7 0}$ & \\
\hline Rata-rata & $\mathbf{9 0 , 8}$ & & & & Baik Sekali \\
\hline
\end{tabular}

Keterangan:

UIC: Unsur Intrinsik Cerpen

HK: Huruf Kapital

Berdasarkan tabel 3 dapat diketahui siswa yang mendapat nilai 100 dengan kualifikasi sempurna berjumlah 10 orang, siswa yang mendapat nilai 95 dengan kualifikasi baik sekali 3 orang, siswa yang mendapat nilai 90 dengan kualifikasi baik sekali berjumlah 3 orang, siswa yang mendapat nilai 85 dengan kualifikasi baik 1 orang, siswa yang mendapat nilai 80 dengan kualifikasi baik berjumlah 7 orang, dan siswa yang mendapat nilai 70 dengan kualifikasi lebih dari cukup berjumlah 1 orang.
Hasil analisis data menunjukkan bahwa tingkat Keterampilan Menulis Kreatif Cerpen Menggunakan Media Audio Siswa Kelas XII SMA Negeri 1 Kecamatan Payakumbuh dilihat indikator penilaian unsur intrinsik cerpen dengan rata-rata nilai 100 berada pada rentangan 96-100\% dengan kualifikasi sempurna. Selanjutnya, tingkat Keterampilan Menulis Kreatif Cerpen Menggunakan Media Audio Siswa Kelas XII SMA Negeri 1 Kecamatan Payakumbuh dilihat dari indikator penilaian penggunaan huruf kapital dengan rata-rata nilai 80,8 berada pada rentangan 76-85\% dengan kualifikasi baik.

Tabel 2. Keterampilan Menulis Kreatif Cerpen Menggunakan Media Audio Ditinjau dari Unsur Intrinsik Cerpen

\begin{tabular}{ccccc}
\hline No & Kode Siswa & Skor & Nilai & Kualifikasi \\
\hline 1 & 01 & 5 & 100 & Sempurna \\
\hline 2 & 02 & 5 & 100 & Sempurna \\
\hline 3 & 03 & 5 & 100 & Sempurna \\
\hline 4 & 04 & 5 & 100 & Sempurna \\
\hline 5 & 05 & 5 & 100 & Sempurna \\
\hline 6 & 06 & 5 & 100 & Sempurna \\
\hline 7 & 07 & 5 & 100 & Sempurna \\
\hline 8 & 08 & 5 & 100 & Sempurna \\
\hline 9 & 09 & 5 & 100 & Sempurna \\
\hline 10 & 010 & 5 & 100 & Sempurna \\
\hline 11 & 011 & 5 & 100 & Sempurna \\
\hline 12 & 012 & 5 & 100 & Sempurna \\
\hline 13 & 013 & 5 & 100 & Sempurna \\
\hline 14 & 014 & 5 & 100 & Sempurna \\
\hline 15 & 015 & 5 & 100 & Sempurna \\
\hline 16 & 016 & 5 & 100 & Sempurna \\
\hline 17 & 017 & 5 & 100 & Sempurna \\
\hline 18 & 018 & 5 & 100 & Sempurna \\
\hline & & & & \\
\hline
\end{tabular}




\begin{tabular}{ccccc}
\hline No & Kode Siswa & Skor & Nilai & Kualifikasi \\
\hline 19 & 019 & 5 & 100 & Sempurna \\
\hline 20 & 020 & 5 & 100 & Sempurna \\
\hline 21 & 021 & 5 & 100 & Sempurna \\
\hline 22 & 022 & 5 & 100 & Sempurna \\
\hline 23 & 023 & 5 & 100 & Sempurna \\
\hline 24 & 024 & 5 & 100 & Sempurna \\
\hline 25 & 025 & 5 & 100 & Sempurna \\
\hline & Jumlah & $\mathbf{N = 2 5}$ & $\sum \mathbf{F x}=\mathbf{2 5 0 0}$ & Sempurna \\
\hline & & $\mathbf{M}=\mathbf{1 0 0}$ & Sempurna \\
\hline
\end{tabular}

Berdasarkan tabel di atas, menentukan unsur intrinsik cerpen Keterampilan Menulis Kreatif Cerpen dijabarkan secara lengkap, yaitu: siswa Menggunakan Media Audio Siswa Kelas yang memperoleh nilai 100 berjumlah 25 XII SMA Negeri 1 Kecamatan orang.

Payakumbuh di tinjau dari aspek

Tabel 3. Klasifikasi tingkat penguasaan Keterampilan Menulis Kreatif Cerpen Menggunakan Media Audio

\begin{tabular}{ccccc}
\hline No & Kualifikasi & Frekuensi & Persentase & $\begin{array}{c}\text { Tingkat } \\
\text { Penguasaan }\end{array}$ \\
\hline 1 & Sempurna & 10 & $40 \%$ & $96-100 \%$ \\
\hline 2 & Baik Sekali & 6 & $24 \%$ & $86-95 \%$ \\
\hline 3 & Baik & 8 & $32 \%$ & $76-85 \%$ \\
\hline 4 & Lebih dari Cukup & 1 & $4 \%$ & $66-75 \%$ \\
\hline 5 & Cukup & - & - & $56-65 \%$ \\
\hline 6 & Hampir Kurang & - & - & $46-55 \%$ \\
\hline 7 & Kurang & - & - & $36-45 \%$ \\
\hline 8 & Kurang Sekali & - & - & $26-35 \%$ \\
\hline 9 & Buruk & - & - & $16-25 \%$ \\
\hline 10 & Buruk Sekali & - & - & $0-15 \%$ \\
\hline & Jumlah & $\mathbf{2 5}$ & $\mathbf{1 0 0 \%}$ & - \\
\hline
\end{tabular}

Nurgiyantoro (dalam Abdurrahman dan Ratna, 2003:265)

Berdasarkan tabel di atas, maka terlihat klasifikasi Keterampilan Menulis Kreatif Cerpen Menggunakan Media Audio Siswa Kelas XII SMA Negeri 1 Kecamatan Payakumbuh yang ditinjau dari dua aspek penilaiaan yaitu: unsur intrinsik cerpen dan penggunaan huruf kapital yang telah diuji, yang ditemukan empat tingkat antaranya: 1) kualifikasi sempurna berjumlah 10 orang dengan persentase $48 \%$; 2) kualifikasi baik sekali berjumlah 6 orang dengan persentase $24 \%$; 3 ) kualifikasi baik berjumlah 8 orang dengan persentase $32 \%$; dan 4) kualifikasi lebih dari cukup berjumlah 1 orang dengan persentase $4 \%$. Dapat dilihat pada grafik berikut ini. 


\section{Grafik 1. Klasifikasi Keterampilan Menulis Kreatif Cerpen Menggunakan Media Audio}

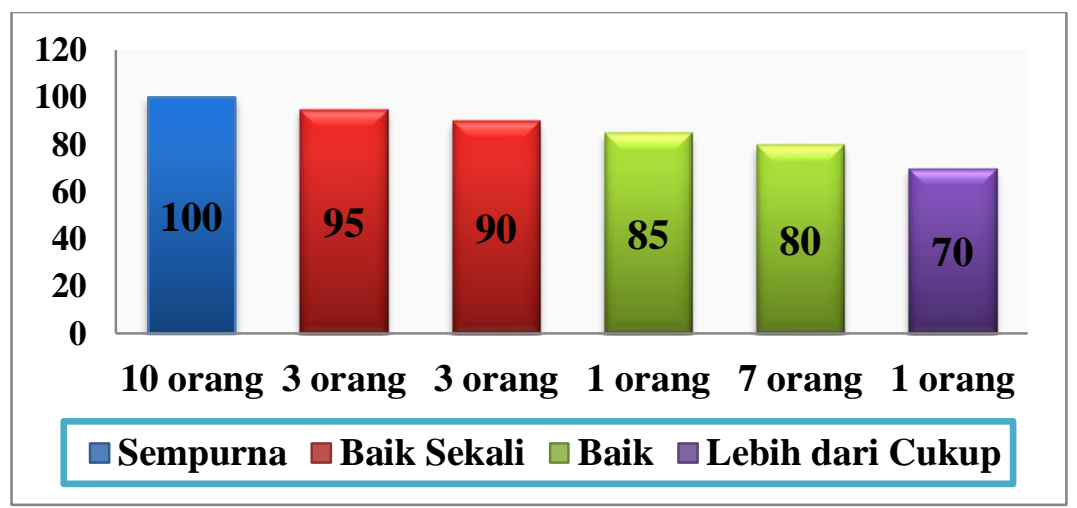

Tabel 4. Keterampilan Menulis Kreatif Cerpen Menggunakan Media Audio Ditinjau dari Penggunaan Huruf Kapital

\begin{tabular}{ccccc}
\hline No & Kode Siswa & Skor & Nilai & Kualifikasi \\
\hline 1 & 01 & 3 & 60 & Cukup \\
\hline 2 & 02 & 4 & 80 & Baik \\
\hline 3 & 03 & 4,5 & 90 & Sempurna \\
\hline 4 & 04 & 4,5 & 90 & Sempurna \\
\hline 5 & 05 & 3 & 60 & Cukup \\
\hline 6 & 06 & 5 & 100 & Sempurna \\
\hline 7 & 07 & 5 & 100 & Sempurna \\
\hline 8 & 08 & 4 & 80 & Baik \\
\hline 9 & 09 & 3 & 60 & Cukup \\
\hline 10 & 010 & 2 & 40 & Kurang \\
\hline 11 & 011 & 3,5 & 70 & Cukup \\
\hline 12 & 012 & 5 & 100 & Sempurna \\
\hline 13 & 013 & 4,5 & 90 & Baik \\
\hline 14 & 014 & 5 & 100 & Sempurna \\
\hline 15 & 015 & 4 & 80 & Baik \\
\hline 16 & 016 & 3 & 60 & Cukup \\
\hline 17 & 017 & 5 & 100 & Sempurna \\
\hline 18 & 018 & 5 & 100 & Sempurna \\
\hline 19 & 019 & 5 & 100 & Sempurna \\
\hline 20 & 020 & 5 & 100 & Sempurna \\
\hline 21 & 021 & 3 & 60 & Cukup \\
\hline 22 & 022 & 5 & 100 & Sempurna \\
\hline 23 & 023 & 5 & 100 & Sempurna \\
\hline 24 & 024 & 3 & 60 & Cukup \\
\hline 25 & 025 & 3 & 40 & Kurang \\
\hline & Jumlah & $\mathbf{2 5}=\mathbf{2 0 2 0}$ & \\
\hline & Rata-rata & & & Baik \\
\hline & & & $\mathbf{M 0 , 8}$ & \\
\hline
\end{tabular}

Berdasarkan tabel di atas huruf kapital dijabarkan secara lengkap, Keterampilan Menulis Kreatif Cerpen yaitu: yang memperoleh nilai 100 Menggunakan Media Audio Siswa Kelas berjumlah 10 orang, yang memperoleh XII SMA Negeri 1 Kecamatan nilai 90 berjumlah 3 orang, yang Payakumbuh ditinjau dari penggunaan memperoleh nilai 80 berjumlah 3 orang, 
yang memperoleh nilai 70 berjumlah 1 orang, yang memperoleh nilai 60 berjumlah 5 orang, dan yang memperoleh nilai 40 berjumlah 2 orang. Untuk lebih jelasnya penskoran penggunaan huruf kapital pada keterampilan menulis cerpen menggunakan media gambar berseri dapat dilihat dibawah ini.

\section{Grafik 2. Nilai Rata-rata Per Indikator}

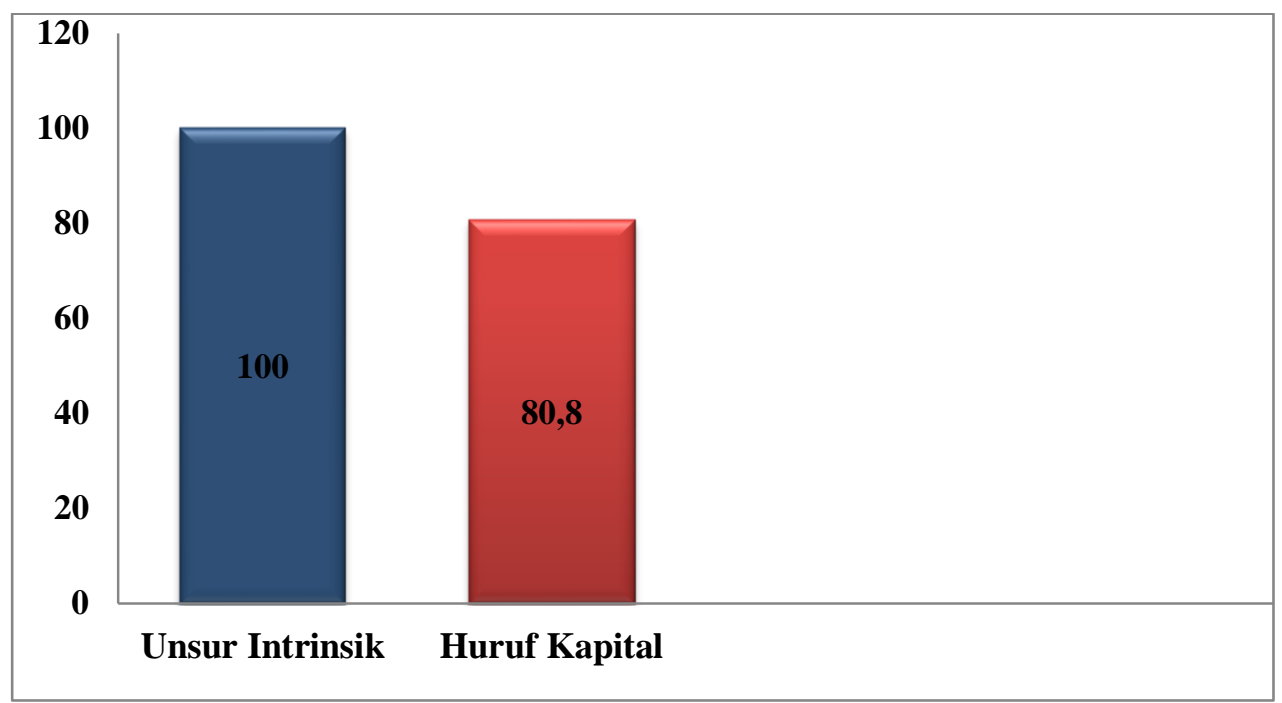

\section{SIMPULAN}

Berdasarkan hasil penelitian terhadap keterampilan menulis cerpen menggunakan media audio kelas XII SMAN I Kecamatan Payakumbuh, dapat disimpulkan sebagai berikut ini.

1. Keterampilan menulis kreatif cerpen menggunakan media audio siswa kelas XII SMAN I Kecamatan Payakumbuh secara umum memiliki nilai rata-rata 90,8 berada pada rentangan $85-96 \%$ dengan kualifikasi baik sekali.

2. Keterampilan menulis kreatif cerpen menggunakan media audio siswa kelas XII SMAN I Kecamatan Payakumbuh dilihat dari unsur intrinsik cerpen memiliki nilai rata-rata 100 berada pada rentangan $96-100 \%$ dengan kualifikasi sempurna.

3. Keterampilan menulis kreatif cerpen menggunakan media audio siswa kelas XII SMAN I Kecamatan Payakumbuh dilihat dari penggunaan huruf kapital memiliki nilai rata-rata 80,8 berada pada rentangan $76-85 \%$ dengan kualifikasi baik.
Jadi, siswa kelas XII SMAN 1 Kecamatan Payakumbuh sudah terampil dalam menulis kreatif cerpen dengan indikator yang telah ditentukan. Berdasarkan kesimpulan di atas, maka penulis memaparkan beberapa saran, yaitu sebagai berikut ini.

1. Sekolah agar dapat memenuhi segala kebutuhan, baik sarana maupun prasarana yang dapat menunjang kegiatan belajar mengajar.

2. Guru mata pelajaran bahasa Indonesia, agar lebih kreatif menggunakan media dalam pembelajaran gunanya untuk meningkatkan minat belajar siswa, sehingga siswa tidak bosan dalam proses belajar mengajari. Agar siswa lebih kreatif lagi.

3. Siswa kelas XII SMAN I Kecamatan Payakumbuh, hendaknya meningkatkan minat belajar dan lebih berlatih lagi dalam kegiatan menulis khususnya menulis kreatif cerpen, sehingga bisa lebih kreatif lagi dalam menulis cerpen.

4. Peneliti, agar dapat melanjutkan penelitian ini dengan menggunakan metode 
lainnya untuk mendapatkan hasil yang lebih baik lagi dari hasil penelitian ini.

\section{PERSANTUNAN}

Kedua orang tua sebagai inspirasi bagi penulis dan memberi motivasi lahir dan batin kepada penulis dalam menyelesaikan artikel jurnal ini.

Ayu Armia Gusti sebagai rekan dalam penelitian ini. Siswa kelas XII SMAN I Kecamatan Payakumbuh, terimakasih atas waktu yang telah disediakan untuk menjawab tes.

\section{DAFTAR PUSTAKA}

Abdurahman, Ellya Ratna. 2003. Evaluasi Pembelajaran Bahasa dan Sastra Indonesia. Buku ajar. Padang : FBSS UNP.

Kosasih. 2011. Apresiasi Sastra Indonesia. Jakarta: Raja Grafindo Persada.

Kusumaningsih, Patmiati dkk. 2007.

Bahasa Indonesia untuk

Mahasiswa. Yogyakarta: Andi

Yogyakarta dengan Universitas

Negeri Jember.

Kusumaningsih, Triyantoro dkk. 2013.

Terampil Berbahasa Indonesia.

Yogyakarta: Andi Offset.

Nurgiyantoro, Burhan. 1998. Teori

Pengkajian Fiksi. Yogyakarta:

Gajah Mada

Nuruddin. 2010. Dasar Dasar Penulisan. Malang: UMM Press.

Sudjana dan Rivai. 2010. Media Pengajaran. Bandung : Sinar Baru Algensindo.

Universitas Press.

Wardhana, Wisnu Arya dan Andi Suryo Ardianto. 2007. Menyingkap Rahasia Jadi Penulis. Yogyakarta: Pustaka Pelajar. 